\title{
Dispositional Coping Styles and Childhood Abuse History Among Japanese Undergraduate Students
}

\author{
Noriko Shikai ${ }^{*}, 1$, Masayo $\mathrm{Uji}^{2}$, Masahiro Shono ${ }^{3}$, Toshiaki Nagata ${ }^{4}$ and Toshinori Kitamura ${ }^{2}$ \\ ${ }^{1}$ Shikai Clinic, Japan \\ ${ }^{2}$ Department of Clinical Behavioural Sciences (Psychological Medicine) Kumamoto University Graduate School of \\ Medical Sciences, Japan \\ ${ }^{3}$ Yuge Hospital, Japan \\ ${ }^{4}$ Kyushu University of Nursing and Social Welfare, Japan
}

\begin{abstract}
Dispositional coping styles in adulthood may be influenced by one's experiences as a child. Japanese university students were examined in terms of their coping styles and child abuse history. Regression analyses revealed that an emotion-oriented coping style was predicted by neglect and emotional abuse during childhood.
\end{abstract}

\section{INTRODUCTION}

Coping styles have been studied intensively in psychology and psychiatry because they are pivotal in predicting psychological adjustment and the onset of a variety of psychopathologies [1-3]. There have been two perspectives on coping with stressful situations $[4,5]$. One perspective views coping as a situationally dependent process whereby people employ a set of skills or responses to manage specific stressful situations. In this model the type of stressor has a consistent and significant effect on the choice of coping response. For example, McCrae [6] reported that positive thinking was employed significantly more frequently when an event was regarded as a challenge than when it was viewed as a loss or threat. Another perspective views coping as part of an individual's habitual interaction with their usually stressful environment. This form of coping is regarded as dispositional and is thus interpreted as part of the individual's personality. In support of this theory, researchers have found correlations between coping styles and personality traits [7-9]. Coping skills used in different situations show moderate correlations with dispositional coping styles $[10,11]$. Thus, one's coping behaviour in real-life stressful situations is derived partly from dispositional coping style.

Personality development is thought to be influenced by both genetic (e.g., [12,13]) and environmental (e.g., [14-16]) factors, and various researchers have sought to identify the early environmental factors that are associated with adult personality traits [16-23]. However, the possible link between these factors and adult dispositional coping styles has not yet been comprehensively examined.

Leitenberg, Gibson, and Novy [24] reported that among undergraduate women, experiencing more types of childhood abuse (sexual abuse, physical abuse, witnessing domestic violence, having an alcoholic parent, and parental rejection) correlated with greater reliance on disengagement

*Address correspondence to this author at the Shikai Clinic, Kumamoto, Japan; E-mail: shikai@hyper.ocn.ne.jp methods of coping (wishful thinking, problem avoidance, social withdrawal, and self-criticism). Shapiro and Levendosky [25] found that adolescents' attachment styles mediated the effects of child abuse on fewer active coping strategies. Hyman, Paliwal, and Sinha [26] reported that among people in the early phases of cocaine abstinence, those with a greater variety of childhood abuse experiences were more likely to use avoidance-oriented coping styles. However, because these studies combined physical abuse, emotional abuse, and neglect under the composite internal variable of "child abuse," it was impossible to examine specific relationships between the different types of child abuse and coping styles.

Among different categories of child abuse, sexual abuse has been frequently studied. The greater the severity of their child sexual abuse, the more likely adults are to use avoidance [27-29], emotive [30], and internalizing [31] coping strategies and the less likely they are to use support seeking [31]. However, abuse severity did not predict approach or avoidance coping strategies in another study [32]. People who were abused verbally as children are more likely to use emotion-oriented coping styles, while people who were physically abused during childhood are less likely to use problem-oriented coping styles [33].

The current study reports on the link between dispositional coping styles and different types of childhood abuse histories among Japanese undergraduate students.

\section{METHOD}

\section{Participants}

Participants were part of a weekly follow-up study (nine Waves) that examined numerous aspects of mental health among Japanese undergraduate students. These students were from two universities in Kumamoto. On different occasions they were distributed sets of questionnaires that included the Coping Inventory for Stressful Situations (CISS) [34] (Wave 1, $\mathrm{n}=389$ ) and the Child Abuse and Trauma Scale (CATS) [35] (Wave 2, $n=397$ ). A varying number of 
students missed a class on different Waves. The total number of students who submitted a dataset containing all variables used in the present analyses was 364 . These students consisted of 70 men and 294 women, with a mean age of 19.0 years (SD 1.3) and an age range between 18 and 35. Men (M $=19.5, \mathrm{SD}=2.3)$ were slightly but significantly $(\mathrm{t}=2.2 \mathrm{p}<$ $.05)$ older than women $(\mathrm{M}=18.8, \mathrm{SD}=0.9)$.

\section{Measurements}

Coping Inventory for Stressful Situations (CISS): The CISS is a self-report measure of coping patterns. It consists of 48 items rated on a five-point scale $(0=$ not at all, $4=$ very much). There are three subcategories - task-oriented coping, emotion-oriented coping, and avoidance-oriented coping. Task-oriented coping is usually adaptive and involves outlining priorities, determining a course of action, and following through with the action involved [2]. Emotion-oriented coping involves blaming oneself for the situation or event and becoming preoccupied about it. Avoidanceoriented coping involves participating in other activities as a way of ignoring the problem. A higher score on a CISS subcategory indicates greater use of that coping style. Furukawa, Suzuki, Saito, and Hamanaka [36] have provided a Japanese translation of the measure, and have demonstrated its reliability and validity. Mean values were substituted for missing items when at least 39 out of 48 CISS items were answered. The CISS was administered on the first Wave.

Child Abuse and Trauma Scale (CATS): The CATS is a self-report measure of the experiences of sexual abuse, neglect, and punishment (physical abuse). It consists of 38 items on a 5 -point scale $(0=$ never, $4=$ always). Sanders and Becker-Lausen [35] have suggested three subcategories: sexual abuse (6 items), neglect (14 items), and punishment (6 items). In the present population, we performed an exploratory factor analysis with Promax rotation. The number of items was determined via the scree test and interpretability of the data. After confirming the factor structure of the Japanese version of the CATS, we calculated the subscale scores by adding the scores of items belonging to each factor [37]. The Japanese version of the CATS consists of five subscales: (1) neglect and emotional abuse (14 items, e.g., "Did your parents insult you or call you names?", "Did you parents ever verbally lash out at you when you did not expect it?", and "Did your parents ridicule you?"), (2) punishment and scolding (10 items, e.g., "Did your parents yell at you?", "How often did your parents get really angry with you?", and "Did your parents blame you for things you didn't do?"), (3) sexual maltreatment, (6 items, e.g., "Did you engage in any sexual activity with an adult?", "Did you ever have traumatic sexual experiences?", and "When either of your parents was intoxicated, were you ever afraid of being sexually mistreated?"), (4) authoritarianism (5 items, e.g., "When you were punished, did you feel 'the punishment fit the crime'?", "When you were punished, did you feel the punishment was deserved?", and "When you were punished, did you understand the reason you were punished?"), and (5) marital disharmony (3 items, e.g., "To what extent did either of your parents drink heavily or abuse drugs?", "Did your parents verbally abuse each other?", and "Were your parents unhappy with each other?"). Mean values were substituted for missing items when at least 31 out of the 38 items were answered.

\section{Procedure}

A class lecturer distributed a set of questionnaires to the university students every week. The questionnaires were returned immediately upon completion during the class. An oral announcement that the students had a right to refrain from participating was made before distributing the questionnaires and was written on the face sheet. It was also announced that refraining would not result in any academic disadvantages. Anonymity was assured, but due to the necessity of matching students to questionnaires they filled out on different occasions, students were requested to create a unique "nickname" and use it whenever they answered a questionnaire. The questionnaire survey was repeated weekly. This study project was approved by the Ethical Committee of the Kumamoto University Graduate School of Medical Sciences (equivalent to an Institutional Review Board).

\section{Statistical Analyses}

After obtaining basic properties of all the variables used, we correlated all variables. In order to examine the predictive power of the child abuse experience for each of the CISS subcategories, we performed a series of regression analyses. Each of the CISS subcategories was regressed on (1) age and gender, and (2) a set of the CATS scores. In addition, we forced the interaction terms of gender and each CATS score into the regression formula.

All statistical analyses were conducted using the Statistical Package for Social Science (SPSS) version 13.0.

\section{RESULTS}

In bivariate analyses, all three CISS subcategory scores were correlated with each other (Table 1). Some of the five child abuse scores were also correlated significantly with each other. Emotion-oriented coping in women was correlated with neglect and emotional abuse and punishment and scolding. Women were significantly more likely to use emotion-oriented and avoidance-oriented coping than men (Table 1).

Regression analyses showed that both emotion-oriented and avoidance-oriented coping were predicted by female gender. After controlling for age and gender, only emotionoriented coping was predicted by childhood abuse history, particularly neglect and emotional abuse (Table 2). The interaction terms between gender and each of the CATS subcategories did not improve prediction of the CISS scores.

\section{DISCUSSION}

The results of this study suggest that childhood neglect is linked to the tendency for undergraduate female students to use emotion-oriented coping. The absence of links between coping styles and other types of child abuse history may be due to the lower prevalence of some forms of maltreatment, particularly sexual abuse. This may be because we examined a non-clinical student population in which child sexual abuse was relatively infrequent, or because the participating students avoided answering uncomfortable questions about their pasts.

This study provides an understanding about the link between adult emotion-oriented coping style and childhood neglect. In several of the previous studies, it is reported that 
Table 1. Basic Properties of and Correlations Between All the Variables Used in This Study for Men and Women

\begin{tabular}{|c|c|c|c|c|c|c|c|c|c|}
\hline & 1 & 2 & 3 & 4 & 5 & 6 & 7 & 8 & 9 \\
\hline 1 Task-Oriented Coping & --- & $.26 *$ & $.52 * * *$ & .21 & $.26 *$ & .18 & .13 & .05 & .19 \\
\hline 3 Avoidance-Oriented Coping & $.34 * * *$ & $.26 * * *$ & --- & .15 & $.30 *$ & $.25 *$ & $.24 *$ & -.00 & .22 \\
\hline 4 Age & .09 & -.03 & .06 & --- & .21 & $.29 *$ & -.09 & .01 & .09 \\
\hline 5 Neglect and Emotional Abuse & .09 & $.33 * * *$ & .05 & .01 & --- & $.81 * * *$ & $.32 * *$ & .13 & $.66 * * *$ \\
\hline 6 Punishment and Scolding & .09 & $.23 * * *$ & .05 & $.14 *$ & $.71 * * *$ & --- & $.33 * *$ & .14 & $.60 * * *$ \\
\hline 7 Sexual Maltreatment & -.01 & $.13 *$ & -.01 & -.04 & $.28 * * *$ & $.30 * * *$ & --- & -.01 & $.43 * * *$ \\
\hline 8 Authoritarianism & $-.15 *$ & .04 & .01 & .00 & $.35 * * *$ & $.22 * * *$ & .11 & --- & $.31 * *$ \\
\hline S.D. ${ }^{a}$ & $\begin{array}{l}12.4 \\
11.9 \\
\end{array}$ & $\begin{array}{c}9.9 \\
11.1 \\
\end{array}$ & $\begin{array}{c}9.7 \\
10.4 \\
\end{array}$ & $\begin{array}{l}2.3 \\
0.9 \\
\end{array}$ & $\begin{array}{l}8.9 \\
9.2 \\
\end{array}$ & $\begin{array}{l}6.3 \\
6.1 \\
\end{array}$ & $\begin{array}{l}1.9 \\
1.0 \\
\end{array}$ & $\begin{array}{l}4.3 \\
4.1 \\
\end{array}$ & $\begin{array}{l}1.9 \\
2.0 \\
\end{array}$ \\
\hline T-test for gender difference & $\mathrm{ns}$ & $\mathrm{p}<.01$ & $\mathrm{p}<.001$ & $\mathrm{p}<.05$ & ns & $\mathrm{ns}$ & ns & $\mathrm{ns}$ & $\mathrm{ns}$ \\
\hline
\end{tabular}

$* p<.05 ; * * p<.01 ; * * * p<.001$ : ns, not significant; Figures over the orthogonal apply to male students, figures below the orthogonal to female students.

Table 2. Regression of CISS Subscale Scores by Age, CATS Scores, and PBI Scores

\begin{tabular}{|l|c|c|c|c|c|c|}
\hline & \multicolumn{2}{|c|}{ Task-Oriented Coping } & \multicolumn{2}{c|}{ Emotion-Oriented Coping } & \multicolumn{2}{c|}{ Avoidance-Oriented Coping } \\
\cline { 2 - 7 } & $\mathbf{R}^{2}$ Increase & $\begin{array}{c}\text { Standardised } \\
\text { Beta }\end{array}$ & $\mathbf{R}^{2}$ Increase & $\begin{array}{c}\text { Standardised } \\
\text { Beta }\end{array}$ & $\begin{array}{c}\text { Standardised } \\
\text { Beta }\end{array}$ \\
\hline \hline Step 1: & $.015(2,361)$ & & $.027(2,361) * *$ & & $.052(2,361) * * *$ & \\
\hline Age & & .117 & & -.060 & & .082 \\
\hline Gender & & .001 & & $.121 *$ & & $.223 * * *$ \\
\hline Step 2: & $.038(5,356)$ & & $.104(5,356) * * *$ & & $.014(5,356)$ & \\
\hline Neglect and Emotional Abuse & & .158 & & $.372 * * *$ & & .066 \\
\hline Punishment and Scolding & & -.023 & & .049 & & -.024 \\
\hline Sexual Maltreatment & & .005 & & -.076 & & .043 \\
\hline Authoritarianism & & $-.168 * *$ & & -.071 & & -.036 \\
\hline Marital Disharmony & & .049 & & & .075 \\
\hline
\end{tabular}

$* p<.05 ; * * p<.01 ; * * * p<.001: \mathrm{df}(\mathrm{v} 1, \mathrm{v} 2)$ in brackets.

the emotion-oriented coping style is related to psychological maladjustment [1-3]. In this vain, the understanding about these two factors may be very important, and it may be of clinical importance to pay attention carefully to the early life experiences among patients whose coping style is emotionoriented. Behavioral approach to "rectify" and make them realize their coping styles is no doubt recommendable but at the same time the thorough scrutiny of their childhood environment may reveal the hidden reasons why they adopt such maladaptive coping styles. Psychotherapeutic intervention into the link between childhood abuse experiences and dispositional coping styles may further the patients' enduring psychological well-being in addition to the current betterment of the coping in an everyday life.
A limitation of this study is the retrospective nature of its assessment methods. While validity of retrospective reports on childhood experiences has been a focus of several debates [38-43], retrospective recall has been shown to correspond well with collateral reports and available archival data [4447].

Another drawback of this study is its lack of information on which parent was abusive, a problem that arises because the CATS asks questions about "parents" rather than about each parent individually. Gender of the parents has been shown to influence the effects of parental physical and emotional abuse on adolescent-onset mood and anxiety disorders [48]. Thus, the present research should be replicated using abuse-related data about the father and mother individually. 
It is also important to examine a larger population that includes both non-clinical and clinical subjects with a wide age range, using psychopathology measurements in addition to those used here. The link between childhood neglect and adult emotion-oriented coping may be mediated by yet another attribute. Personality traits such as neuroticism and low self-directedness may be possible candidates.

\section{CONCLUSION}

Despite these drawbacks, this study suggests that adult dispositional coping styles may be in part influenced by childhood abuse history, particularly among female students. Further studies may clarify the links between abuse history and the onset of psychopathology.

\section{REFERENCES}

[1] Lazarus RS, Folkman S. Stress, appraisal, and coping. New York: Springer 1984.

[2] Penley JA, Tomaka J, Wiebe JS. The association of coping to physical and psychological health outcomes: A meta-analytic review. J Behav Med 2002; 25: 551-603.

[3] Snyder CR, Ford CE, Eds. Coping with negative life events: clinical and social psychological perspectives. New York: Plenum 1987.

[4] Beutler E, Moos RH, Lane G. Coping, treatment planning, and treatment outcome: discussion. J Clin Psychol 2003; 59: 1151-67.

[5] Moos R, Holahan CJ. Dispositional and contextual perspectives on coping: Toward an integrative framework. J Clin Psychol 2003; 59: 1387-403.

[6] McCrae RR. Situational determinants of coping responses: Loss, threat, and challenge. J Pers Soc Psychol 1984; 46: 919-28.

[7] Johnson DM, Sheahan TC, Chard KM. Personality disorders, coping strategies, and posttraumatic stress disorder in women with histories of childhood sexual abuse. J Child Sex Abuse 2003; 12: 1939.

[8] O'Brien TB, DeLongis A. The interactional context of problem-, emotion-, and relationship-focused coping: The role of the big five personality factors. J Pers 1996; 64: 775-813.

[9] Vollrath M, Torgersen S, Alnæs R. Personality as long-term predictor of coping. Pers Indiv Diff 1995; 18: 117-25.

[10] Carver CS, Scheier MF, Weintraub JK. Assessing coping strategies: A theoretically based approach. J Pers Soc Psychol 1989; 58: 267-83.

[11] Ptacek JT, Piece GR, Thompson EL. Finding evidence of dispositional coping. J Res Pers 2006; 40: 1137-51.

[12] Heath AC, Madden PA, Cloninger CR, Martin NG. Genetic and environmental structure of personality. In Cloninger CR, Ed. Personality and Psychopathology, Washington D.C.: American Psychiatric Association 1999; pp. 343-67,

[13] Loranger AW, Oldham JM, Tulis EH. Familial transmission of DSM-III borderline personality disorder. Arch Gen Psychiatry 1982; 39: 795-9.

[14] Bowlby J. The influence of early environment in the development of neurosis and neurotic character. Int J Psycho-Anal 1940; 21: 154-78.

[15] Ferenczi S. Confusion of tongues between the adult and the child. Int J Psychoanal 1947; 30: 225-30.

[16] Ruchkin VV, Eisemann M, Hägglöf B, Cloninger CR. Interrelations between temperament, character, and parental rearing in male delinquent adolescents in Northern Russia. Comp Psychiatry 1998; 39: 225-30.

[17] Benjaminsen S, Jorgensen J, Kragh-Hansen L, Pedersen LL. Memories of parental rearing practices and personality features. Acta Psychiatr Scand 1984; 69: 426-434.

[18] Kendler KS, Kessler RC, Neale MC, Heath AC, Eaves LJ. The prediction of major depression in women: toward an integrated etiologic model. Am J Psychiatry 1993; 150: 1139-48.

[19] Kitamura T, Fujihara S. Understanding personality traits from early life experiences. Psychiatry Clin Neurosci 2003; 57: 323-31.

[20] Kitamura T, Kishida Y. Early experiences and development of personality: A study of the Temperament and Character Inventory in 4000 university students in Japan. In: Kingler LV, Ed. Trends in lifestyle and health research, pp. 1-20, Hauppauge: Nova Science Publishers 2005.

[21] Kitamura T, Tomoda A, Kijima N, Sakamoto S, Tanaka E, Iwata N. Correlates of retrospective early life experience with personality in young Japanese women. Psychol Rep 2002; 91: 263-74.

[22] Ono Y, Yoshimura K, Mizushima H, et al. Environmental and possible genetic contributions to character dimensions of personality. Psychol Rep 1999; 84: 689-696.

[23] Reti IM, Samuels JF, Eaton WW, Bienvenu OJ III, Costa PT Jr, Nestadt G. Influence of parenting on normal personality traits. Psychiatr Res 2002; 111: 55-64.

[24] Leitenberg H, Gibson LE, Novy PL. Individual differences among undergraduate women in methods of coping with stressful events: The impact of cumulative childhood stressors and abuse. Child Abuse Negl 2004; 28: 181-92.

[25] Shapiro DL, Levendosky AA. Adolescent survivors of childhood sexual abuse: The mediating role of attachment style and coping in psychological and interpersonal functioning. Child Abuse Negl 1999; 23: 1175-91.

[26] Hyman SM, Paliwal P, Sinha R. Childhood maltreatment, perceived stress, and stress-related coping in recently abstinent cocaine dependent adults. Psychol Addict Behav 2007; 21: 233-8.

[27] Bal S, Crombez G, Van Oost P, Debourdeaudhuij I. The role of social support in well-being and coping with self-reported stressful events in adolescents. Child Abuse Negl 2003; 27: 1377-95.

[28] Bal S, Van Oost P, De Bourdeaudhuij I, Crombez G. Avoidant coping as a mediator between self-reported sexual abuse and stressrelated symptoms in adolescents. Child Abuse Negl 2003; 27: 88397.

[29] Runtz MG, Schallow JR. Social support and coping strategies as mediators of adult adjustment following childhood maltreatment. Child Abuse Negl 1997; 21: 211-26.

[30] Rew L, Christian B. Self-efficacy, coping, and well-being among nursing students sexually abused in childhood. J Pediatr Nurs 1993; 8: 392-9.

[31] Steel J, Sanna L, Hammond B, Whipple J, Cross H. Psychological sequelae of childhood sexual abuse: Abuse-related characteristics, coping strategies, and attributional style. Child Abuse Negl 2004; 28: 785-801.

[32] Tremblay C, Hébert M, Piché C. Coping strategies and social support as mediators of consequences in child sexual abuse victims. Child Abuse Negl 1999; 23: 929-45.

[33] Thabet AAA, Tischler V, Vostanis P. Maltreatment and coping strategies among male adolescents living in the Gaza Strip. Child Abuse Negl 2004; 28: 77-91.

[34] Endler NS, Parker JDA. Coping Inventory for Stressful Situations: Manual Toronto: Multi-Health Systems 1991.

[35] Sanders B, Becker-Lausen E. The measurement of psychological maltreatment: early data on the child abuse and trauma scale. Child Abuse Negl 1995; 19: 315-23.

[36] Furukawa T, Suzuki A, Saito Y, Hamanaka T. Reliability and validity of the Japanese version of the Coping Inventory for Stressful Situations (CISS): A contribution to the cross-cultural studies of coping. Psychiatria et Neurologia Japonica 1993; 95: 602-21. (in Japanese)

[37] Igarashi H, Hasui C, Uji M, Shono M, Nagata T, Kitamura T. Borderline and narcissistic personality traits: Their relationship with childhood abuse experiences among a student population in Japan 2008; (in preparation)

[38] Glickman L, Hubbard M, Liveright T, Valciukas JA. Fall-off in reporting life events: Effects of life change, desirability, and anticipation. Behav Med 1990; 16: 31-8.

[39] Hepp U, Gamma A, Milos G, Eich D, Ajdacic-Gross V, Rösser, W, Angst J, Schnyder U. Inconsistency in reporting potentially traumatic events. Br J Psychiatry 2006; 188: 278-83.

[40] Jenkins CD, Hurst MW, Rose RM. Life changes: do people really remember? Arch Gen Psychiatry 1979; 36: 379-84.

[41] Maughan B, Rutter M. Retrospective reporting of childhood adversity: issues in assessing long-term recall. J Pers Disord 1997; 11: 19-33.

[42] Monroe SM. Assessment of life events: retrospective $v s$ concurrent strategies. Arch Gen Psychiatry 1982; 39: 606-10.

[43] Widom CS. Sampling biases and implications for child abuse research. Am J Orthopsychiatry 1988; 58: 260-70. 
[44] Brewin CR, Andrews B, Gotlib IH. Psychopathology and early experience: a reappraisal of retrospective reports. Psychol Bull 1993; 113: 82-98

[45] Herman JL, Schatzow E. Recovery and verification of memories of childhood sexual trauma. Psychoanal Psychol 1987; 4: 1-14.

[46] Widom CS, Shepard RL. Accuracy of adult recollections of childhood victimization: Part 1. Childhood physical abuse. Psychol Assess 1996; 8: 412-21.
[47]

Widom CS, Shepard RL. Accuracy of adult recollections of childhood victimization: Part 1. Childhood sexual abuse. Psychol Assess 1997; 9: 34-46.

[48] Yamamoto M, Tanaka S, Fujimaki K, Iwata N, Tomoda A, Kitamura $\mathrm{T}$. Child emotional and physical maltreatment and adolescent psychopathology: A community study in Japan. J Community Psychol 1999; 27: 377-91.

(C) Shikai et al.; Licensee Bentham Open.

This is an open access article licensed under the terms of the Creative Commons Attribution Non-Commercial License (http://creativecommons.org/licenses/by$\mathrm{nc} / 3.0 /$ ) which permits unrestricted, non-commercial use, distribution and reproduction in any medium, provided the work is properly cited. 